\title{
A successful healthy live birth from a female patient with hypogonadotropic hypogonadism and oocytes with unusually large cytoplasmic inclusions
}

\author{
Candan İltemir Duvan ${ }^{1}$, Aslıhan Pekel ${ }^{1}$, Ummu Gulsum Ercan ${ }^{1}$, Yuksel Onaran Arıkan ${ }^{1}$ \\ ${ }^{1}$ Turgut Ozal University, School of Medicine, Department of Obstetrics and Gynecology, IVF Clinic, Ankara, Turkey
}

\begin{abstract}
This study aimed to report the case of a successful live birth from a woman having oocytes with abnormally large cytoplasmic inclusions. The patient described in this case is a 28 year-old woman with hypogonadotropic hypogonadism $(\mathrm{HH})$ with a history of two previous unsuccessful in vitro fertilization (IVF) attempts offered an antagonist protocol. Stimulation was performed with human menopausal gonadotropin $300 \mathrm{IU} /$ day. The intracytoplasmic sperm injection (ICSI) procedure was performed 4-6 hours after oocyte aspiration for all mature oocytes. Six oocytes were retrieved, five of which mature (MII). All oocytes had abnormal cytoplasmic structures. Two were fertilized after ICSI and two top quality embryos were transferred on Day 2. Our case report suggests that $\mathrm{HH}$ patients with refractile bodies/lipofuscin in their oocytes may not have their pregnancies negatively affected. While there have been several reports of successful births from dysmorphic oocytes, no cases of successful pregnancies followed by live births from young women with $\mathrm{HH}$ and oocytes with large cytoplasmic inclusions had been reported to date.
\end{abstract}

Keywords: Refractile body, Lipofuscin, Oocyte Cytoplasm, ICSI

\section{INTRODUCTION}

Oocyte morphology is an important factor in female fertility and a reflection of the intrinsic developmental potential of the oocyte; additionally, it plays an important role in fertilization and subsequent embryo development (Gilchrist et al., 2008). According to some data, the phenotype of the adult stage offspring is considerably defined by the quality of the oocytes from which they are derived (Mtango et al., 2008). Different kinds of oocyte dysmorphisms have been identified in humans. They can be extracytoplasmic or cytoplasmic anomalies (Mikkelsen \& Lindenberg, 2001; Ebner et al., 2006). It has been reported that the development of intracytoplasmic and extracytoplasmic anomalies during the maturation process may lead to fertilization failure (Ebner et al., 2006; De Sutter et al., 1996; Rienzi L et al., 2008), chromosome aneuploidy (Kahraman et al., 2000; Van Blerkom \& Henry,1992), and developmental impairment of the embryo despite normal fertilization (Xia P, 1997). Analysis of the literature, however, shows that the effect of oocyte morphologic deviations after ICSI remains controversial (Balaban \& Urman, 2006; Balaban et al., 1998). In the literature, different anomalies of oocyte morphology have been described (Van Blerkom \& Henry,1992). Refractile bodies are one of the main morphological abnormalities in the cytoplasm of oocytes. They include lipid bodies, small autophagic vacuoles, and lipofuscin bodies. These inclusions may range in size from 1 to $5 \mu \mathrm{m}$. Large inclusions ( $>5 \mu \mathrm{m}$ ) have been associated with lower chance of fertilization and blastocyst development rate (Otsuki et al., 2007).
In 1912, Hueck presented the term lipofuscin, based on lipo (Greek for fat) and fuscus (Latin for dark), consisting of aggregated polymers derived from the oxidation products of lipids and proteins. Lipofuscin is autofluorescent (Browne \& Rippin, 1977; Collins \& Brunk, 1976) and related to aging with continuous accumulation over time within post-mitotic cells such as neurons (Glees \& Hasan, 1976; Sohal \& Brunk, 1989) and cardiac myocytes (Munnell \& Getty, 1968). Experimental data have shown that the cytoplasmic accumulation of lipofuscin in cells is accelerated by increased oxygen levels (Sohal \& Brunk, 1989; Munnell \& Getty, 1968; Gao, 1994 ) and by inhibitors of lysosomal proteases and lipases (Marzabadi et al., 1991), suggesting that oxidative stress and the incomplete degradation of autophagocytosed material may cause lipofuscinogenesis by the accumulation of peroxidized lipids and proteins in secondary lysosomes (Terman, 1995). The underlying mechanism that causes the occurrence of refractile bodies is unknown. A correlation between morphology, developmental competence, and chromosomal abnormalities has not been clearly established.

\section{CASE REPORT}

A 28-year old woman diagnosed with hypogonadotropic hypogonadism with a history of two previous unsuccessful IVF attempts came to our IVF clinic in March of 2013. Her hormone profile on the third day of menstruation cycle was as follows: FSH: $0.6 \mathrm{mIU} / \mathrm{ml}, \mathrm{E} 2: 22.7 \mathrm{pg} / \mathrm{ml}$, $\mathrm{LH}:<0.07 \mathrm{mIU} / \mathrm{ml}$, PRL: $9.4 \mathrm{ng} / \mathrm{ml}, \mathrm{P} 2: 0.3 \mathrm{ng} / \mathrm{ml}$, AMH: $0.3 \mathrm{ng} / \mathrm{ml}$. Controlled ovarian stimulation was achieved with the use of human menopausal gonadotropin (HMG) 375 IU/day as a daily dose, starting on Day 3 of the cycle. Follicular development was monitored by serial transvaginal ultrasonography and serum E2 levels. Pituitary blockage was performed with a GnRH antagonist (Cetrotide; Serono) given when at least one follicle reach $14 \mathrm{~mm}$. When the mean follicle size reached $17 \mathrm{~mm}$, an injection of $250 \mu \mathrm{g}$ of recombinant human chorionic gonadotropin (hCG, Ovitrelle; Serono) was given to trigger the final stages of oocyte maturation; ultrasound-guided oocyte pick-up was performed 35-36 hours later. Six oocytes were retrieved, five of which mature (MII). The intracytoplasmic sperm injection (ICSI) procedure was performed 4-6 hours after oocyte aspiration for all mature oocytes. Fertilization check was done 16-18 hours after ICSI. The embryos were transferred on Day 2. The luteal phase was supported with a daily $8 \%$ progesterone gel (Crinone; Serono) started on the day of oocyte retrieval (Table 1 ).

Two of the mature oocytes were fertilized and cleaved in culture medium. Two 4-cell grade I embryos were transferred on Day 2. A pregnancy test carried out 12 days after transfer showed a $\beta$-hCG level of $62.7 \mathrm{mIU} / \mathrm{mL}$, which increased to $158 \mathrm{mIU} / \mathrm{mL}$ two days later. A singleton pregnancy with a visible heart beat was detected at gestational week 7. All oocytes had abnormal cytoplasmic structures, 
Table 1. Patient clinical characteristics

\begin{tabular}{|l|c|}
\hline Age (years) & 28 \\
\hline Basal serum FSH $(\mathrm{mIU} / \mathrm{ml})$ & 0.6 \\
\hline Basal serum E2(pg/ml) & 22.7 \\
\hline Days of stimulation $($ day) & 300 \\
\hline Daily dose $(\mu \mathrm{IU} /$ day) & 3675 \\
\hline Total dose $(\mathrm{IU})$ & 1138 \\
\hline Estradiol at the time of hCG administration $(\mathrm{pg} / \mathrm{ml})$ & 6 \\
\hline Total number of retrieved oocytes & 5 \\
\hline Metaphase II oocytes & 1 \\
\hline Metaphase I oocyte & $2 / 5)$ \\
\hline ICSI fertilization $\%)$ & $40(2 / 5)$ \\
\hline Transferred & 4 cell G1, 4 cell G1 \\
\hline
\end{tabular}

Figure 1: Large fractile body/lipofuscin in the oocytes $(a, b, c, d, e, f)$

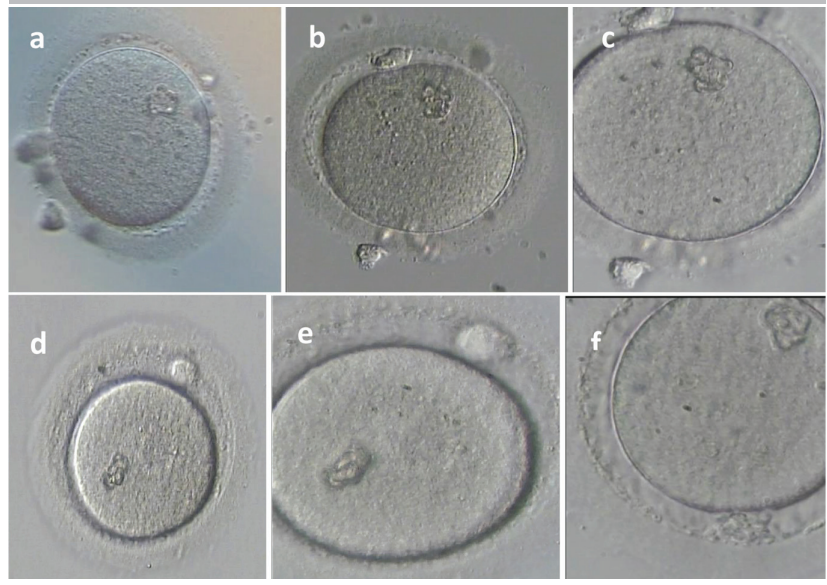

resembling an accumulation of refractile bodies, although atypically large (Figure1). However, the material could be the same, which is lipofuscin. They did not disappear after fertilization, and were still seen after cleavage in one blastomere (Figure 2). According to the literature, trace inclusions may persist up to the blastocyst stage. However, larger inclusions usually end up in a cell which either stops developing or goes to trophectoderm. But since this inclusion was too big for a trophectoderm cell, the affected cell may be excluded from the embryo.

\section{DISCUSSION}

The female gamete plays a crucial role in determining embryo competence and, therefore, in vitro fertilization (IVF) outcomes. Oocyte quality is influenced by the nuclear and mitochondrial genome and by the microenvironment provided by the ovary and the pre-ovulatory follicle, which by its turn affects transcription and translation and, consequently, cytoplasmic maturity. In contrast with in vivo processes, the use of ovarian stimulation in human reproduction further complicates the already complex selection procedure that usually occurs during oocyte development and maturation of a single oocyte for ovulation, while allowing for the maturation of many oocytes, often with compromised quality (Rienzi et al., 2008). It has been shown in the literature that severe dysmorphisms of the cytoplasmic texture impairs the developmental and implantation potential of the embryo (Balaban \& Urman, 2006).

According to some authors, cytoplasmic inclusions do
Figure 2: Large refractile body/lipofuscin after fertilization $(\mathrm{g}, \mathrm{h})$ and in one blastomere of embryos (i)
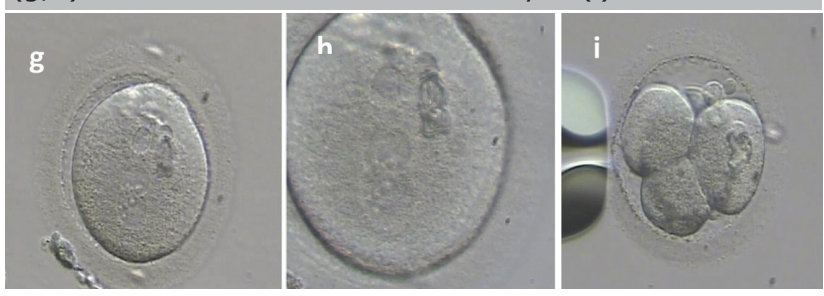

not seem to affect fertilization, embryo quality, or implantation rates (De Sutter et al., 1996; Balaban \& Urman, 2006). Others, however, have reported decreased fertilization and embryo development (Xia, 1997; Otsuki et al., 2007). Negative impacts from specific intracytoplasmic and extracytoplasmic oocyte defects on the blastocyst quality parameters have been reported (Braga et al., 2013).

Hypogonadotropic hypogonadism $(\mathrm{HH})$ has been classified as a Group I anovulation disorder by the World Health Organization (WHO). Individuals with $\mathrm{HH}$ are good candidates for ovulation induction with exogenous gonadotropins. $\mathrm{HH}$ is usually idiopathic, with no anatomical lesions in the pituitary stalk. The condition is characterized by amenorrhea, hypoestrogenism, low serum gonadotropins, and a broad spectrum of abnormal secretion patterns of hypothalamic gonadotropin releasing hormone (GnRH) (Reame et al., 1985). Ovulation induction can be achieved with small doses of menotropins. The conventional procedure is to start ovulation with lower daily doses of human menopausal gonadotropins (hMG). In our patient the starting dose of menotropins was high and the course of gonadotropin administration was long (12 days). The high doses prescribed to the patient may have affected oocyte metabolism. The occurrence of large refractile bodies/lipofuscin bodies may be related to the status of perifollicular blood circulation and follicular fluid composition seen in patients with $\mathrm{HH}$.

There are no studies comparing abnormal oocyte morphology according to infertility etiology. The formation of refractile bodies/lipofuscin has been correlated to oxidative stress (Veeck, 1991). It has also been suggested that the occurrence of lipofuscin may be related to the metabolism of lipids into energy. Potential interactions between adipokines and the hypothalamus, pituitary gland, ovary, oocyte, embryo, and female reproductive tract such as insulin resistance have been suggested (Van Blerkom, 1990). 


\section{CONCLUSIONS}

The predictive value of oocyte cytoplasmic morphology has been a topic of controversy in the literature. Our case report suggests that the pregnancies of patients with $\mathrm{HH}$ and refractile body/lipofuscin in their oocytes may not be adversely affected. While there have been several reports of successful births from dysmorphic oocytes, no cases of successful pregnancies followed by live births from women with $\mathrm{HH}$ and oocytes with large cytoplasmic inclusions had been reported to date.

\section{CONFLICT OF INTERESTS}

No conflict of interest have been declared.

\section{Corresponding author:}

Aslıhan Pekel

Turgut Ozal University, School of Medicine, Department of Obstetrics and Gynecology, IVF Clinic Ankara, Turkey

E-mail: aslipekel@yahoo.com

\section{REFERENCES}

Balaban B, Urman B, Sertac A, Alatas C, Aksoy S, Mercan R. Oocyte morphology does not affect fertilization rate, embryo quality and implantation rate after intracytoplasmic sperm injection. Hum Reprod 1998;13:3431-3.

Balaban B, Urman B. Effect of oocyte morphology on embryo development and implantation Reprod Biomed Online. $2006 ; 12: 608-15$.

Braga DP, Setti AS, Figueira Rde C, Machado RB, Iaconelli A Jr, Borges E Jr. Influence of oocyte dysmorphisms on blastocyst formation and quality. Fertil Steril. 2013;100:748-54.

Browne RM, Rippin JW. Autofluorescent granular cells in oral mucosal hyperplasias. Histopathology. 1977;1:375-84.

Collins VP, Brunk UT. Characterization of residual bodies formed in phase II cultivated human glia cells. Mech Ageing Dev 1976;5:193-207.

De Sutter P, Dozortsev D, Qian C, Dhont M. Oocyte morphology does not correlate with fertilization rate and embryo quality after intracytoplasmic sperm injection. Hum Reprod 1996;11:595-7.

Ebner T, Moser M, Tews G. Is oocyte morphology prognostic of embryo developmental potential after ICSI? Reprod Biomed Online. 2006; 12: 507-12.

Gao G, Ollinger K, Brunk UT. Influence of intracellular glutathione concentration of lipofuscin accumulation in cultured neonatal rat cardiac myocytes. Free Radic Biol Med 1994;16:187-94.

Gilchrist RB, Lane M, Thompson JG. Oocyte-secreted factors: regulators of cumulus Cell function and oocyte quality. Hum Reprod Update 2008;14:159-77.

Glees P, Hasan M. Lipofuscin in neuronal aging and diseases. Norm Pathol Anat 1976; 32:1-68.
Kahraman S, Yakin K, Donmez E, Samli H, Bahce M, Cengiz G, Sertyel S, Samli M, Imirzalioğlu N. Relationship between granular cytoplasm of oocytes and pregnancy outcome following intracytoplasmic sperm injection. Hum Reprod. 2000;15:2390-3.

Marzabadi MR, Sohal RS, Brunk UT. Mechanisms of lipofuscinogenesis: effect of the inhibition of lysosomal proteinases and lipases under varying concentrations of ambient oxygen in cultured rat neonatal myocardial cells. APMIS. $1991 ; 99: 416-26$.

Mikkelsen AL, Lindenberg S. Morphology of in-vitro matured oocytes: impact on fertility potential and embryo quality. Hum Reprod. 2001; 16: 1714-8.

Mtango NR, Potireddy S, Latham K. Oocyte quality and maternal control of development. Int Rev Cell Mol Biol $2008 ; 268: 223-90$.

Munnell JF, Getty R. Rate of accumulation of cardiac lipofuscin in the aging canine. J Gerontol 1968;23:154-8.

Otsuki J, Nagai Y, Chiba K. Lipofuscin bodies in human oocytes as an indicator of oocyte quality. J Assist Reprod Genet $2007 ; 24: 263-70$.

Reame NE, Sauder SE, Case GD, Kelch RP, Marshall JC. Pulsatile gonadotropin secretion in women with hypothalamic amenorrhea: Evidence that reduced frequency of gonadotropin-releasing hormone secretion is the mechanism of persistent anovulation. J Clin Endocrinol Metab $1985 ; 61: 851-858$.

Rienzi L, Ubaldi FM, Iacobelli M, Minasi MG, Romano S, Ferrero S, Sapienza F, Baroni E, Litwicka K, Greco E. Significance of metaphase II human oocyte morphology on ICSI outcome. Fertil Steril 2008;90:1692-700.

Sohal RS, Brunk UT. Lipofuscin as an indicator of oxidative stress and aging. Adv Exp Med Biol 1989;266:17-29.

Terman A. The effect of age on formation and elimination of autophagic vacuoles in mouse hepatocytes. Gerontology 1995;41:319-26.

Van Blerkom J. Occurrence and developmental consequences of aberrant cellular organization in meiotically mature human oocytes after exogenous ovarian hyperstimulation. J ElectronMicroscTech 1990;16: 324-46.

Van Blerkom J, Henry G. Oocyte dysmorphism and aneuploidy in meiotically mature human oocytes after ovarian stimulation. Hum Reprod 1992; 7: 379-90.

Veeck LL, ed. Atlas of the human oocyte and early conceptus. Baltimore: Williams \& Wilkins; 1991.

Xia P. Intracytoplasmic sperm injection: correlation of oocyte grade based on polar body, perivitelline space and cytoplasmic inclusions with fertilization rate and embryo quality. Hum Reprod 1997;12: 1750-5. 